\title{
ANTERIOR TRANSFER OF THE TOE FLEXORS FOR EQUINOVARUS DEFORMITY DUE TO HEMIPLEGIA
}

\author{
SADAO MORITA, HARUYASU YAMAMOTO, KOHTARO FURUYA
}

From Tokyo Medical and Dental University, Japan

We report the results of transfer of the long toe flexors and lengthening of the calcaneal tendon in 33 patients with equinovarus deformity requiring orthoses after a stroke.

Review of 29 patients more than two years after surgery showed that 21 were able to walk without an orthosis. Equinovarus deformity had recurred in six patients and hammer toe in 11, but walking ability without bracing was still better in seven of these. Results are improved by the release of the short toe flexors.

J Bone Joint Surg [Br] 1994; 76-B:447-9.

Received 4 October 1993; Accepted 9 December 1993

Equinovarus deformity is common after a cerebrovascular accident. This may impair walking, and is usually treated by the use of an ankle-foot orthosis (McCollough 1975). Surgical treatment by tendon transfer and lengthening of the calcaneal tendon has also been reported to give good results (Mooney and Goodman 1969; Tracy 1976; Ono et al 1980). Both treatments have merit, but severe spasticity makes the wearing of an orthosis difficult, and many with moderate deformity would prefer to walk unbraced.

We report the results of the surgical treatment of equinovarus deformity in 33 patients after stroke.

\section{PATIENTS AND METHODS}

From 1982 to 1986 , we performed anterior transfer of the long toe flexors for equinovarus deformity due to cerebrovascular disease in 33 patients. Twenty-nine were followed for at least two years, with an average followup of 38 months (24 to 60). Two were lost to follow-up and two died within two years of surgery. The average age of the patients was 58 years ( 40 to 70$)$ and the average

S. Morita, MD, Assistant Professor

H. Yamamoto, MD, Associate Professor

K. Furuya, MD, Professor

Department of Orthopaedic Surgery, Tokyo Medical and Dental University, 1-5-45, Yushima, Bunkyo-ku, Tokyo 113, Japan.

Correspondence should be sent to Dr S. Morita.

(C)1994 British Editorial Society of Bone and Joint Surgery

0301-620X/94/3796\$2.00 interval from the onset of hemiplegia to operation was 29 months (6 to 85$)$. Of the 29 patients, 20 were male and ten had left-sided hemiplegia. Eleven patients could walk with a cane outdoors, 11 with a cane indoors only, and seven with a cane under supervision.

All had been treated in an ankle-foot orthosis before surgery. Seven found this too difficult because of the severity of equinovarus deformity, and nine with less severe deformity could not walk without the orthosis. The other 13 could walk without the orthosis but were at risk of falling because of the lack of a plantigrade foot and difficulty in weight transfer on the affected limb (Table I).

We recorded walking ability before surgery, at four months after surgery and at the latest follow-up, measuring speed over $10 \mathrm{~m}$.

Operative technique. At operation, the long toe flexor tendons are transferred through the interosseous membrane to the fourth metatarsal, and the calcaneal tendon is lengthened (Ono et al 1980). A $15 \mathrm{~cm}$ incision is made posteriorly in the lower leg (Fig. 1; A), and the calcaneal tendon is lengthened enough to allow $10^{\circ}$ dorsiflexion of the ankle with the knee extended. Flexor hallucis longus (FHL) tendon is divided through an incision (B) at the base of the big toe. The tendons of flexor digitorum longus (FDL) and their fibrous slips to FHL are divided through an incision (C) on the medial aspect of the foot.
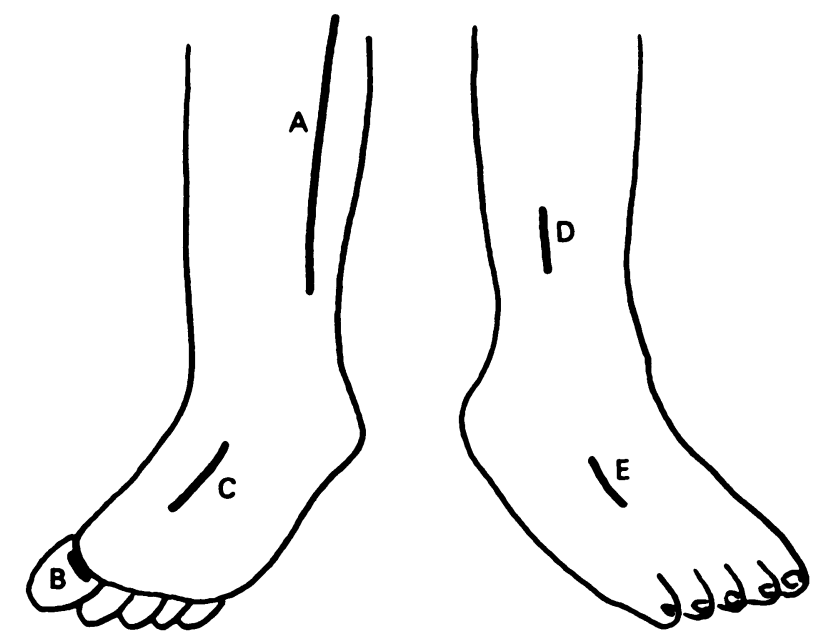

Fig. 1

Diagrams to show the sites of the five skin incisions, $A$ to $E$. 
Table I. Use of brace before and after operation in 29 patients

\begin{tabular}{lccl}
\hline & Before & \multicolumn{2}{l}{ Follow-up } \\
\cline { 4 - 5 } & operation & At four months & At 24 to 60 months \\
\hline Not needed & 0 & 25 & 21 \\
Sometimes uses brace & 0 & 4 & 5 \\
Always uses brace & 22 & 0 & 3 \\
Difficulty in using brace & 7 & 0 & 0 \\
\hline
\end{tabular}

The freed tendons are withdrawn from the foot through the posterior incision. The distal parts of their tibial and fibular origins are elevated for about $7 \mathrm{~cm}$ to expose the interosseous membrane, which is widely opened and excised. An anterolateral incision (D) allows the tendons to be pulled out through the interosseous membrane, followed by part of their muscle bellies. They are passed subcutaneously to an incision (E) over the base of the fourth metatarsal which is then exposed and stripped of its periosteum. The FHL tendon is passed around the base of the fourth metatarsal to form a loop, and sutured to the FDL tendons using an interlacing technique under maximum tension, with the ankle in maximum dorsiflexion (Fig. 2).

In addition, the posterior tibial tendon was lengthened in five patients who before surgery had varus deformity of the hindfoot on walking. The short toe flexors were released in three patients through a plantar incision for severe hammer toe.

A below-knee cast is worn for four weeks postoperatively, full weight-bearing in the cast being allowed after two weeks. After its removal an ankle-foot orthosis is used for about four weeks, with gait training after discontinuing the brace.

\section{RESULTS}

At four months after surgery, hammer-toe deformity had recurred in four patients. At the latest follow-up, equinovarus deformity had recurred in six $(21 \%)$ and hammer toe in $11(38 \%)$. There was no recurrence of hammer toe in the patients who had release of the short toe flexors.

At four months, four patients still needed a brace to obtain toe clearance when walking outdoors (Table I). At the latest follow-up 21 patients (72\%) were able to walk without an orthosis, five (17\%) only used braces to walk outdoors and three $(10 \%)$ always used an orthosis. None had difficulty in wearing orthoses because of foot deformities.

Walking velocity improved from an average of $24.1 \mathrm{~m} / \mathrm{min}$ in braces before surgery to $29.8 \mathrm{~m} / \mathrm{min}$ with no braces at four months (Fig. 3), 22 patients being able to walk faster without a brace. In general, walking ability was improved in 13 and unchanged in 16 at four months after surgery. At the latest follow-up, seven patients had maintained their improved walking ability (Table II).

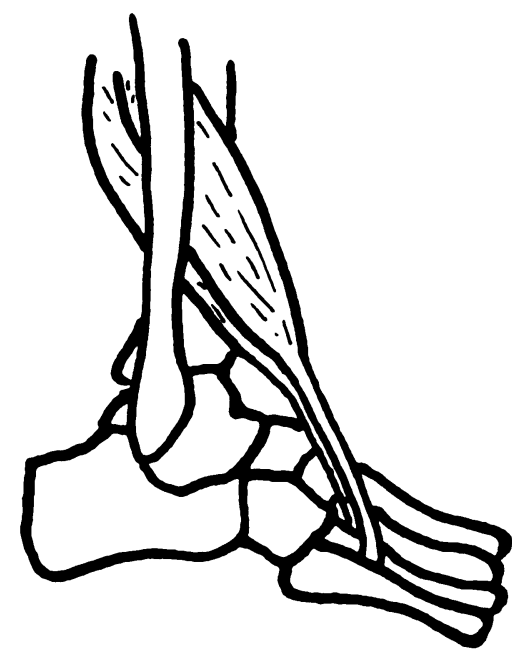

Fig. 2

Diagram to show the rerouted long toe flexors. The FHL and FDL tendons are pulled through a large window in the interosseous membrane. FHL tendon is passed around the base of the fourth metatarsal to make a loop, and sutured to FDL tendon by interlacing under maximum tension.

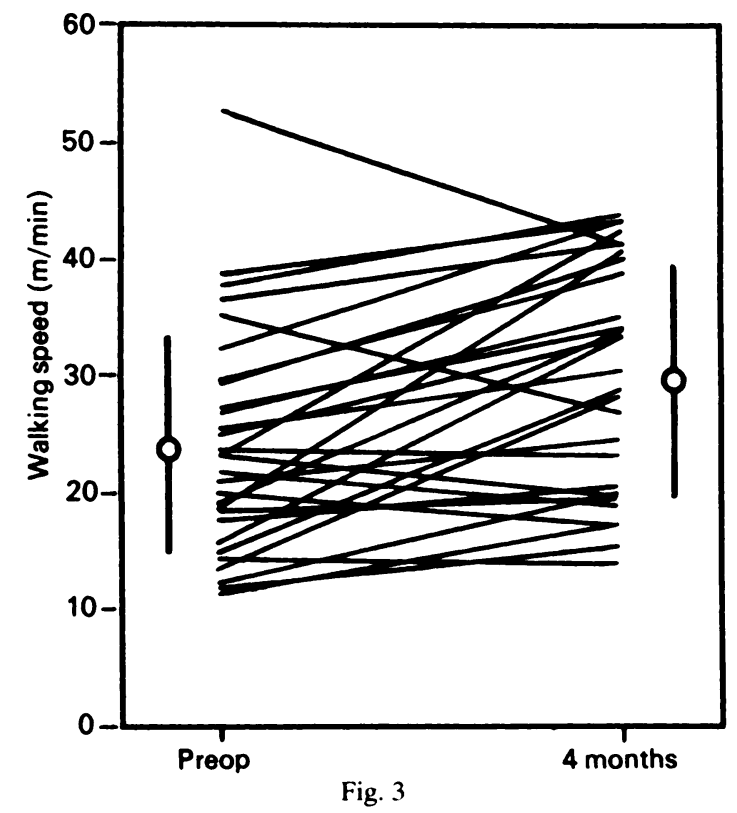

Walking speeds with a brace before operation and without a brace at four months. The circles and vertical lines show meanvalues and standard deviations.

Table II. Walking ability of 29 patients before and after operation

\begin{tabular}{|c|c|c|c|}
\hline & \multirow{2}{*}{$\begin{array}{l}\text { Before } \\
\text { operation }\end{array}$} & \multicolumn{2}{|l|}{ Follow-up } \\
\hline & & At four months & At 24 to 60 months \\
\hline $\begin{array}{l}\text { No cane indoors; } \\
\text { cane outdoors }\end{array}$ & $\mathbf{0}$ & 2 & 1 \\
\hline Cane indoors and outdoors & 11 & 15 & 14 \\
\hline Cane indpors only & 11 & 10 & 9 \\
\hline Cane and assistance & 7 & 2 & 5 \\
\hline
\end{tabular}


One case of superficial infection settled with antibiotics, and there were no peripheral circulatory problems, rupture of transferred or elongated tendons, or other significant complications.

\section{DISCUSSION}

Equinovarus deformity is one of the most common problems after a stroke, rendering the gait laborious and unsafe. Orthoses can provide stability in the stance phase and allow adequate toe clearance in the swing phase but surgery is indicated when the deformity is so severe that wearing an orthosis is difficult or there is pain on walking with a brace. In addition, some patients have difficulty in using an orthosis and request surgery. Of seven such patients, four were able to walk without using one and the other three had no difficulty with their brace at latest review. Of the 22 patients who wished to eliminate the orthosis, 17 were able to do so at the latest follow-up.

Surgery for equinovarus deformity after stroke also aims at stability in the stance phase and restoration of ankle dorsiflexion. In equinovarus deformity with hammer toe, the procedure which we describe seems satisfactory. Alternatives to the long toe flexors to restore ankle dorsiflexion include the tibialis posterior and tibialis anterior tendons. Some of our other patients showed strong active contraction of the anterior tibialis in the swing phase but could not dorsiflex the ankle after transfer of that tendon. Waters, Perry and Garland (1978) also described drop foot which required orthotic support even after transfer of the anterior tibialis tendon. Transfer of the posterior tibialis tendon may produce planovalgus deformity (Ono et al 1980) and this muscle does not contract in the swing phase (Waters et al 1982). We chose the long toe flexors because they are known to show a relatively high incidence of muscle activity in hemiplegic patients in the swing phase (Waters et al 1982). Even if there is no activity after transfer, the tenodesis effect will maintain a neutral position of the ankle during walking.

At four months after surgery, deformities were well corrected in all except four patients with residual hammer toe, but at 24 to 60 months equinovarus had recurred in six $(21 \%)$ and hammer toe in $11(38 \%)$. We believe that recurrent equinovarus is due to remaining imbalance, possibly related to the increased leg spasticity after surgery. Hammer toe did not recur after release of the short toe flexors.

Improved walking ability in 13 patients at four months was maintained in only seven, and some of the early improvement may have been due to physical therapy and gait training for the corrected feet. We had not expected an increase in walking speed.

At 24 to 60 months, some $70 \%$ or more of our patients did not require an orthosis, suggesting that in this respect the result was lasting, and that anterior transfer of the long toe flexors is a worthwhile procedure for equinovarus deformity after stroke.

No benefits in any form have been received or will be received from a commercial party related directly or indirectly to the subject of this article.

\section{REFERENCES}

McCollough NC III. Orthotic management. In: AAOS Instructional Course Lectures. St Louis: CV Mosby, 1975; XXIV:29-40.

Mooney V, Goodman F. Surgical approaches to lower extremity disability secondary to strokes. Clin Orthop 1969; 63:142-52.

Ono K, Hiroshima K, Tada K, Inoue A. Anterior transfer of the toe flexors for equinovarus deformity of the foot. International Orthopaedics 1980; 4:225-9.

Tracy HW. Operative treatment of the plantar-flexed inverted foot in adult hemiplegia. J Bone Joint Surg [Am] 1976; 58-A:1142-5.

Waters RL, Frazier J, Garland DE, Jordan C, Perry J. Electromyographic gait analysis before and after operative treatment for hemiplegic equinus and equinovarus deformity. J Bone Joint Surg [Am] 1982; 64-A:284-8.

Waters RL, Perry J, Garland D. Surgical correction of gait abnormalities following stroke. Clin Orthop 1978; 131:54-63. 